\title{
Cloud-Based E-Governance in India
}

\author{
C. Vijai \\ Assistant Professor, Department of Commerce \\ St. Peter's Institute of Higher Education and Research, Chennai, Tamil Nadu, India \\ D.ttp://orcid.org/0000-0003-0041-7466

\section{Joyce} \\ Assistant Professor, Department of Commerce \\ St. Peter's Institute of Higher Education and Research, Chennai, Tamil Nadu, India
}

\section{OPEN ACCESS}

Manuscript ID:

MGT-2020-08023334

Volume: 8

Issue: 2

Month: October

Year: 2020

P-ISSN: 2321-4643

E-ISSN: 2581-9402

Received: 24.07 .2020

Accepted: 28.09.2020

Published: 01.10.2020

Citation:

Vijai, C., and D. Joyce.

"Cloud-Based E-Governance

in India." Shanlax

International Journal of

Management, vol. 8, no. 2,

2020, pp. $72-78$.

DOI:

https://doi.org/10.34293/

management.v8i2.3334

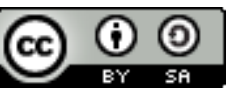

This work is licensed under a Creative Commons Attribution-ShareAlike 4.0 International License.

\begin{abstract}
In the current digital world, the Internet is changing our lives in terms of the way we work, learn, and interact. Cloud Computing has a platform for sharing resources that include infrastructures, software, applications; the cloud is the best way to integrate all departments using e-Governance and business. Many Governments facing critical challenges to maintain pending, unattended documents, reported to the authority, document proof of the statement, law, and order unable to solve over the year. Cloud-based e-governance plays a vital role in solve these issues helping to e-governance services. Citizens easily access government services and provide transparent activities with the help of cloud e-governance applications. This paper discusses cloud computing and cloud-based e-governance in India and to adopt cloud computing in e-Governance applications, challenges and also extended to the usage of cloud-based e-governance.

Keywords: Cloud Computing Services, ITC, India, E-Governance and Cloud-Based E-Governance
\end{abstract}

\section{Introduction}

The overwhelming success and the rapid growth of the Internet change our lives, the way we interact, learn and work (Smitha, K.et al, 2012). In recent years cloud computing is one of the most significantly achieved developments in the IT industry which gives a platform to use the application in the form of services which are more scalable, reliable, high performance and relatively low cost as compared to other distributed computing infrastructure (Dash, S., $\&$ Pani, S. K, 2016). At the same time, we can notice that the governments are also proactive and are planning new ways of interacting, improving services, optimizing processes, and revitalizing democracy by increasing the IT spend. It aims to deliver more interactive services to citizens and businesses through e-governance (Varshney, R. 2018). Cloud Computing is the latest Information Technology revolution that helps developing countries to implement their E-governance services at a very low cost and provide better services to their citizens (Rastogi. A, 2010)

\section{Review of literature}

Singh. A (2019) Cloud itself is a virtualization of resources like networks, applications, servers, services, and data storage and allows on-demand access for the users. Due to the numerous advantages of cloud computing - the government sector is also affected. In this paper, I give an overview, how cloud computing grows in the government sector across the globe. Maurya, S., \& Mukherjee, K (2018). Cloud itself is a virtualization of resources like networks, applications, servers, services, and data storage and allows on-demand access for the users. Due to the numerous advantages of cloud computing - the government sector is also affected. 
Johar, A. et al. (2019) Cloud computing offers features like availability and scalability, reliability, fault-tolerance, and an environment to incorporate big data. Although big data workouts much of the present issues, but it still has quiet issues, or we can say some gaps that raise worries and need refinement. Data heterogeneity, security, disaster recovery mechanisms, scalability, privacy, data governance policies, and other challenges are yet to be addressed. Zittrain, J. L.(2019) To understand where digital governance is going, we must take stock of where it's been because the timbre of mainstream thinking around digital governance today is dramatically different than it was when the study of "Internet governance" coalesced in the late 1990s. Clarke, A (2017) Digital Government Units (DGUs) have quickly emerged as a preferred solution for tackling the over-cost and under-performing digital services and lagging digital transformation agendas plaguing today's governments. DGUs represent common machinery of government phenomenon insofar as they all exist at the center of the state and adopt a shared orthodoxy, favoring agile, user-centric design, open-source technologies, pluralistic procurement, data-driven decision-making, horizontal 'platform' based solutions, and a 'delivery-first' ethos.

\section{Cloud Computing}

Definition of cloud computing is "it is the use of different services such as software development platform, servers, storage and software through the internet referred as the cloud computing" a Significant distributed computing model guided by economic caution of equilibrium in which isolated, basic, loading stake, a platform in which installations are provided through the internet as requested by overseas customers" (Khandelwal, M., \& Saini, H, 2019)

Table 1: Traditional IT Differs from Cloud Computing

\begin{tabular}{|l|c|l|}
\hline \multicolumn{1}{|c|}{ Description } & Traditional IT & \multicolumn{1}{c|}{ Cloud } \\
\hline $\begin{array}{l}\text { Utilization of IT } \\
\text { Resources }\end{array}$ & Low & Optimum \\
\hline Procurement Cycle & Yong & Quick \\
\hline $\begin{array}{l}\text { Capital outlays } \\
\text { for hardware \& } \\
\text { applications }\end{array}$ & No \\
\hline
\end{tabular}

\begin{tabular}{|l|c|l|}
\hline $\begin{array}{l}\text { Flexible IT } \\
\text { infrastructure }\end{array}$ & No & Yes \\
\hline Built-in scalability & No & Yes \\
\hline Maintenance & $\begin{array}{l}\text { Maintenance is } \\
\text { required }\end{array}$ & $\begin{array}{l}\text { Focused } \\
\text { on usage } \\
\text { rather than } \\
\text { maintenance }\end{array}$ \\
\hline Pricing model & Fixed & Variable \\
\hline $\begin{array}{l}\text { Technology } \\
\text { Obsolescence }\end{array}$ & $\begin{array}{c}\text { Taken care by } \\
\text { the organization } \\
\text { itself }\end{array}$ & $\begin{array}{l}\text { Taken care } \\
\text { by the Cloud } \\
\text { Service } \\
\text { Provider }\end{array}$ \\
\hline
\end{tabular}

Source: https://nceg.gov.in/sites/default/files/CloudSanjay\%20Goel.pdf

Cloud Computing has become a significant milestone in the development of Information Systems (IS) and a salient IT strategy for governments, due to offering highly - scalable computing resources (Qahwaji, R. S)

\section{List of Cloud Service Providers}

There are many Cloud Service providers in the market:

1. Amazon Web Service (AWS)

2. Microsoft Azure

3. Google Cloud Platform

4. IBM Cloud Services

5. Adobe Creative Cloud

6. Kamatera

7. VMware

8. Rackspace

9. Red Hat

10. Salesforce

11. Oracle Cloud

12. SAP

13. Verizon Cloud

14. Navisite

15. Dropbox

Cloud computing is a general term for anything that involves delivering hosted services over the internet. These services are divided into three main categories: infrastructure as a service (IaaS), platform as a service (PaaS), and software as a service ( $\mathrm{SaaS})$ (Rouse, M, 2020). 


\section{Figure 1: Cloud Computing Architecture}

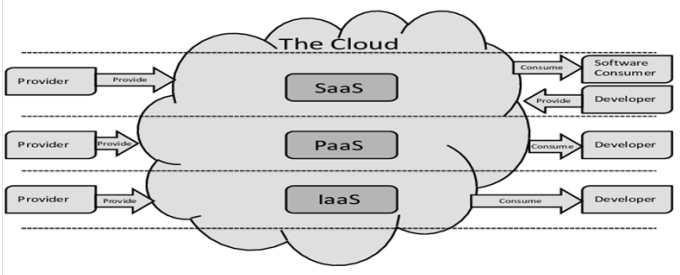

Source: https://www.researchgate.net/figure/CloudComputing-Architecture_fig1_256191449

\section{Cloud-Based E-Governance}

Cloud computing has become another buzzword after Web 2.0. However, there are dozens of different definitions for cloud computing, and there seems to be no consensus on what a cloud is. On the other hand, cloud computing is not a completely new concept; it has an intricate connection to the relatively new but thirteen-year established grid computing paradigm, and other relevant technologies such as utility computing, cluster computing, and distributed systems in general(I. Foster, Y. Zhao, I. Raicu and S. Lu, 2008)

Nowadays, E-government has witnessed widespread adoption in several countries; nonetheless, it's not powerful enough to fulfill the necessities of public services. Therefore the government's demands, considering impacts of knowledge explosion, low potency, and difficulties unitedly. This downside might be solved by applying a cloud computing model to the business method of E-government and building government cloud.

\section{Cloud-Based E-Governance in India}

The Government of India is transcending from traditional modus operandi of governance towards technological involvement in the process of governance. Currently, the Government of India is in the transition phase and seamlessly unleashing the power of ICT in governance (Kumar, P. et al. 2020).

In India too, as of now, nearly every state government has its e-Governance model. Cloud computing is now being widely used in e-governance. With the help of the features of Cloud computing, e-Governance operations can be built up as cost-effective technology solutions. They can be geographically distributed to heterogeneous resources, thereby increasing the quality of service to the users. G-cloud (Governance on Cloud) is designed for using Government services. It is not merely enough to set up e-governance models, but its awareness amongst masses is equally important (S. Shibu and A. Naik, 2017)

\section{Indian Government Initiative (GI Cloud-MeghRaj) MeghRaj}

The Government of India has embarked upon an ambitious initiative - "GI Cloud" which has been named as 'MeghRaj' (https://digitalindia.gov. in) MeghRaj (In Sanskrit 'Megh' means Cloud \& 'Raj' means King), India's 'Cloud-King' project is a Government of India's initiative to adopt Cloud Computing Technology for e-Governance from December 2013. MeghRaj will be a bridge between various Indian Government departments, different State Government departments, Citizens, business enterprises using the internet, and mobile services. The aim is to reduce time, money, and complexities in day-to-day official processes (GlobIndian 2014)

On February 4, 2014, Former Union Minister of Communications and Information Technology, Kapil Sibal, launched the National Cloud under "MeghRaj" Initiative. Some of the features of the National Cloud included a self-service portal, multiple Cloud solutions, secured Virtual Private Network (VPN) access, and multi-location Cloud-Based on nodes that were set up across India in National Data Centres of National Informatics Centre (NIC). This gave Departments a choice of hosting their applications in any of the nodes (IndraStra, 2018)

\section{Figure 2: GI Cloud (MeghRaj) Architecture}

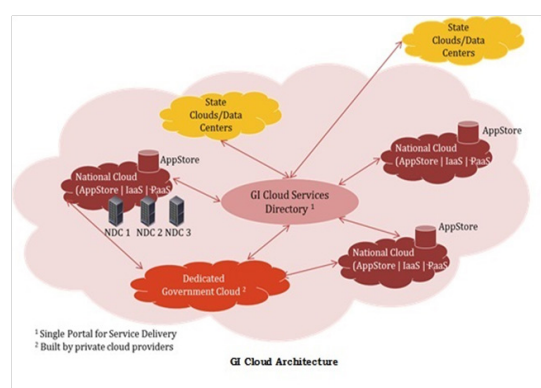

Source: https://meity.gov.in/archive-GI-Cloud

Components of MeghRaj (https://meity.gov.in)

- Setting up of State and National Clouds

- $\quad$ Set up an e-Gov Appstore 
- Empanelment of Cloud Service Providers

- Empanelment of Cloud Auditors

- Setting up of Cloud Management Office

- Setting up an eco-system for Cloud proliferation (Policies, Guidelines, templates, security norms, certification, business models for applications, tariff $\&$ revenue models for private sector Cloud services)

- Awareness workshops, training programs, and migration support for cloud adoption by departments

- MeghRaj (GI-Cloud) service Directory

- Setting up of Clouds by other Government entities.

\section{GI Cloud Eco-System}

Figure 3: GI Cloud Eco-System

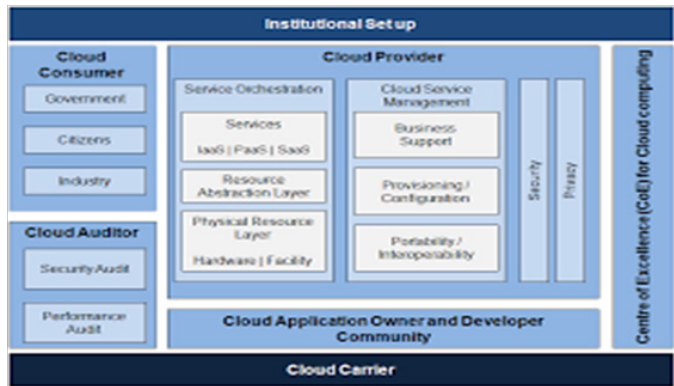

Source: https://meity.gov.in/

The GI Cloud eco-system defines eight key actors in the envisaged GI Cloud Environment (as defined under the section 'GI Cloud Architecture').

These actors include the Institutional Set up, Cloud Consumer, Cloud Auditor, Cloud Carrier, Cloud Provider, Centre of Excellence (CoE) for Cloud Computing and Cloud Application Owner, and Developer Community. Each of these actors is an entity (a person or an organization) or a community that participates in the eco-system, and has specific roles and performs specific tasks (Akanksha Garg et al., 2016). Here are the initiatives are taken by the government of India to encourage cloud technology acceptance:

\section{E-Gram Panchayat}

The cloud model of e-Gram Panchayat depicts a high-level architecture intended to facilitate internal government operations (Priyanka Chaudhari 2019).
Five major cloud models for e Panchayat:

1. Cloud Consumer

2. Cloud Provider

3. Cloud Carrier

4. Cloud Auditor

5. Cloud Broker

Figure 4: e-Panchayat

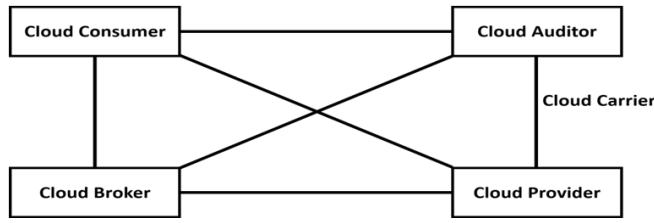

Source: www.esds.co.in

\section{NIVARAN - a Grievance Portal Launched on Rail Cloud}

NIVARAN-Grievance Portal' is the first IT application to be launched on the Rail Cloud. It is the platform for the resolution of servicerelated grievances of serving and former railway employees. The existing application was hosted on a conventional server; it has been made cloud-ready and being migrated as the first cloud application of Indian Railways. It will save significant revenue, and at the same time, the user experience will also improve (https://news.indianrailways.info)

\section{E-Gov Applications on NIC Cloud}

Figure 5: E-Gov Applications on NIC Cloud

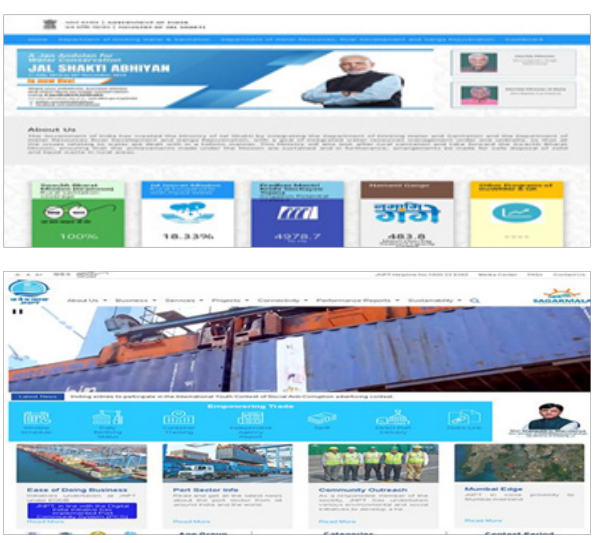




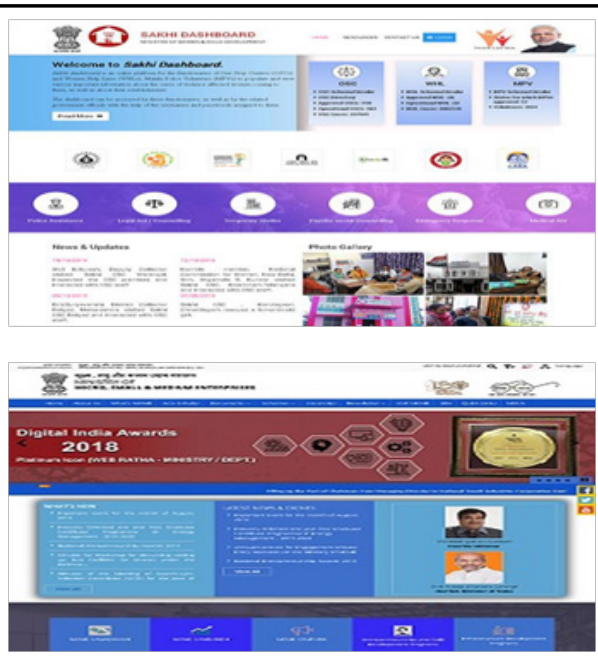

Source: https://cloud.gov.in/

\section{Cloud E-Governance Challenges}

The initial challenge is the government is losing the management of information. This will be a giant issue as trust may be the first key for the adoption of cloud computing, and since information is kept within the cloud, the govt. must reassure of information protection on a constant level if the info is kept domestically.

Recently, our government has begun to utilize cloud computing architectures, platforms, and applications to deliver services and meet the requirements of their constituents. encompassing the employment of cloud computing area unit several risks that may have major impacts on the knowledge and services supported by this technology

Third parties square measure allowed to access sensitive knowledge while not security reinforcement, like multi-factor authentication

Lack of policy to enforce audit rules to ensure compliance (McDonald, R., 2020)

Computing Performance: Cloud Computing is an on-demand to calculate service and supports multitenancy; therefore, performance mustn't suffer over the acquisition of recent users. The CSP ought to maintain enough resources to serve all the users and any ad-hoc requests.

\section{Governance Solutions for Success}

Successful, trendy businesses want these three elements for a good cloud governance answer. First, they have to be able to take a photograph of their existing infrastructure security posture. This may permit them to spot any errors and fix them. They have to attain their compliance to avoid penalties and additional significantly, forestall security breaches. Next, directors have to be compelled to be alerted to changes to their security configuration that would negatively impact their compliance. Finally, they ought to leverage automation to assist fix misconfigurations before they become breaches. With none one amongst those 3 pillars, security is simply temporary.

\section{Conclusion}

Government activities are converted to technology to help citizen access transparent and easier. Cloud computing helps to share resources with the help of software, applications. E-Governance using distribution services required a lot an infrastructure, secured storage, with the help of cloud computing applications. Indian government adopting cloud computing in E-Governance application, it helps to increase security, storage infrastructure, and reduce the cost of the platform. Security aspects especially file transfer internally or externally from one network to another network easier and secured with the help of cloud computing. Governance service focus to create and maintain wider and efficient delivery of services to citizen effectively.

\section{References}

"5 Top Cloud Service Providers Companies in the World." Data Flair, https://data-flair.training/ blogs/cloud-service-providers-companies/

Addo-Yobo, Michael. "Cloud Security Governance Optimizing the Business Benefits of Security in the Cloud." Coalfire, 2018.

Alkhwaldi, Abeer, et al. "Analysis of Cloud-based E-government Services Acceptance in Jordan: Challenges and Barriers." https://core.ac.uk/ reader/161875002.

Almarabeh, Tamara, et al. "Cloud Computing of E-Government." Communications and Network, vol. 8, 2016, pp. 1-8.

Al Mudawi, Naif, et al. "Issues and Challenges: Cloud Computing e-Government in Developing Countries." International Journal of Advanced Computer Science and 
Applications, vol. 11, no. 4, 2020, pp. 7-11.

"Approach and Methodology." Digital India Programme, Ministry of Electronics \& Information Technology, Government of India.

Bourne, James. "7 Reasons Why Cloud Governance is a Challenge: Should we Eradicate Shadow IT?" CloudTech, 2014.

Chanchary, Farah Habib and Samiul Islam. "E-government based on Cloud Computing with Rational Inference Agent." International Conference on High-capacity Optical Networks and Emerging Technologies, 2011.

Chaudhari, Priyanka. "How the Govt of India is Relying on Cloud Technology to reach the Masses." ESDS, 2019.

Clarke, Amanda. "Digital Government Units: Origins, Orthodoxy and Critical Considerations for Public Management Theory and Practice." 2017.

"Cloud Computing Challenges." EDUCBA, https://www.educba.com/cloud-computingchallenges

Das, Rama Krushna, et al. "Adoption of Cloud Computing in e-Governance." International Conference on Computer Science and Information Technology, 2011, pp. 161-172.

Dash, Satyabrata, and Subhendu Kumar Pani. "E-Governance Paradigm Using Cloud Infrastructure: Benefits and Challenges." Procedia Computer Science, vol. 85, 2016, pp. 843-855.

Garg, Akanksha, et al. "Meghraj (Gi Cloud)." International Journal of Innovative Science, Engineering \& Technology, vol. 3, no. 11, 2016, pp. 124-127.

Goodenough, Oliver R. "Governance for Cloud Computing: The Role of Public and Private Rulemaking in Promoting the Growth of a New Industry." Vermont Law School Paper No. 34-13, 2013.

"How to Start a Cloud Governance Framework in Your Organization.” CloudCheckr, 2019.

"Indian Railways to Harness the Power of Cloud Computing in a big way." Indian Railways, 2017.
Jacob, Kamal. "Cloud Computing and the Indian Government." Manipal Pro Learn, 2020.

Johar, Aakriti, et al. "A Study of Big Data Security in Cloud Computing." Proceedings of 4th International Conference on Computers and Management (ICCM), 2018, pp. 116-120.

Khandelwal, Manish Kumar, and Hukam Chand Saini. "Review on Security Challenges of Cloud Computing." International Conference on Advancements in Computing \& Management (ICACM-2019), 2019, pp. 1031-1037.

Kumar, Puneet, et al. "E-Governance in India: Definitions, Challenges and Solutions." International Journal of Computer Applications, vol. 101, no. 16, 2014, pp. 6-8.

Maurya, Sudhanshu, and Kuntal Mukherjee. "Application of Cloud Computing in Governance: An Overview." Research Journal of Computer and Information Technology Sciences, vol. 4, no. 6, 2016, pp. 14-19.

McDonald, Ryan. "How to Overcome the Top 4 Cloud Management Challenges (with Azure)." 10 $0^{\text {th }}$ Magnitude, 2019.

"MeghRaj - India's Cloud Initiative." IndraStra, 2018, https://medium.com/indrastra/meghrajindias-cloud-initiative-7a534b5ce065

"MeghRaj: India is Going to the Cloud (Computing)..." Glob Indian, 2013.

Ministry of Electronics and Information Technology, Government of India, https://meity.gov.in/ archive-GI-Cloud

Mukherjee, Sourav. "Information Governance for the Implementation of Cloud Computing." 2019, https://papers.ssrn.com/sol3/papers. cfm?abstract id $=3405102$

Paquette, Scott, et al. "Identifying the Security Risks associated with Governmental Use of Cloud Computing." Government Information Quarterly, vol. 27, no. 3, 2010, pp. 245-253.

Patil, Monali K., and Roopali Lolage. (2011, November 07). "Cloud Computing Resource Management for Indian E-Governance." International Conference on Computational Intelligence and Information Technology, 2011, pp. 392-395. 
Price, Brian. "4 Reasons Why Cloud Governance Srivastava, Nidhi. "An E-Governance Architecture Matters." Cloudtamer, 2018.

Rastogi, Ashish. "Application of Cloud Computing for the Better E-Governance in Developing Countries." Oriental Journal of Computer Science \& Technology, vol. 3, no. 2, 2010, pp. 343-348.

"Recently, the Government of India has launched a new initiative called MeghRaj. What is this MeghRaj? GK Today.

Rouse, Margaret. "Cloud Computing." TechTarget.

Singh, Ajit. "Smart Governance with Cloud Computing." 2019, https://papers.ssrn.com/ sol3/papers.cfm?abstract_id=3396697

Sivagurunathan, S., and L.S.Swasthimathi. Cloud Computing Applications in Education through E-Governance: An Indian Perspective, IGI Global, 2016.

Smitha, K.K., et al. "Cloud-Based E-Governance System: A Survey." Procedia Engineering, vol. 38, 2012, pp. 3816-3823. using Cloud Computing Technology." 2nd International Conference on Advanced Computing and Software Engineering, 2019, pp. 253-256.

Tripathi, Aprna, and Bhawana Parihar. "E-Governance Challenges and Cloud Benefits." IEEE International Conference on Computer Science and Automation Engineering, 2011, pp. 351-354.

Varshney, Rashi. "Cloud Computing for e-governance." Express Computer, https:// www.expresscomputer.in/columns/cloudcomputing-for-e-governance/14475.

Yellapragada, Anantha. "Opportunities and Challenges for Cloud Adoption in the Indian Government." Yash Technologies, 2019.

Zittrain, Jonathan. "Three Eras of Digital Governance." https://papers.ssrn.com/sol3/ papers.cfm?abstract_id $=3458435$

\section{Author Details}

Dr. C. Vijai, Assistant Professor, Department of Commerce, St. Peter's Institute of Higher Education and Research, Chennai, Tamil Nadu, India, Email ID: vijaialvar@gmail.com.

Mrs. D. Joyce, Assistant Professor, Department of Commerce, St. Peter's Institute of Higher Education and Research, Chennai, Tamil Nadu, India, Email ID: djjoycedaniel23@gmail.com. 